\title{
Development of an Additional System for Wheel Bearing Protection
}

\author{
Jan Steininger ${ }^{1}$, Peter Spisak $^{1}$, Frantisek Brumercik ${ }^{2 *}$ and Igor Gajdac ${ }^{2}$ \\ ${ }^{1}$ University of Zilina, Institute of Competitiveness and Innovations, Univerzitna 8215/1 01026 \\ Zilina, Slovakia; Email: jan.steininger@fstroj.uniza.sk, peter.spisak@fstroj.uniza.sk \\ ${ }^{2}$ University of Zilina, Faculty of Mechanical Engineering, Univerzitna 8215/1 01026 Zilina, \\ Slovakia; Email:frantisek.brumercik@fstroj.uniza.sk,igor.gajdac@fstroj.uniza.sk
}

\section{*Corresponding Author: Frantisek Brumercik}

Received: 8 October 2020; Revised: 25 October 2020; Accepted: 28 October 2020; Published: 30 November 2020

\begin{abstract}
The main goal of the article is to describe the development and production of a prototype of an additional system for wheel motor bearing protection using additive technologies. These technologies include rapid prototyping and vacuum casting. These technologies greatly facilitate and speed up the whole process of developing a new component. Before the development itself, it was necessary to digitize the wheel hub using reverse engineering technology. Using a 3D scanner, a part model was created, based on which an additional system for wheel bearing protection was designed for the CAD system. The dimensional analysis of the produced prototypes was performed. Prototypes of the protection system made of different materials will be tested in common operation conditions.
\end{abstract}

Keywords: Bearing protection, additive technologies, prototype, reverse engineering

\section{Introduction}

An electric vehicle propulsion is becoming increasingly popular. One of the possibilities is the use of a wheeled motor, which saves space and also simplifies the construction of the vehicle itself. However, when we are talking about a vehicle that should be used in difficult terrain, it is necessary to think about higher maintenance requirements, or to take into account the reduced service life of certain groups of parts. One of the parts that are most affected by these influences are the wheels and the hub together with the bearing. These must be checked regularly to prevent the bearing from seizing up and subsequently damaging the hub.

The bearing protection system has great influence on the service life of the wheel hub and the components stored in it. The main task of this system is to prevent the ingress of various impurities and liquids into the rolling bearing, which reduces the overall life of the bearing. The seal used is 
not sufficient protection against dirt under excessive load $[1,2]$. It is necessary to design additional protection of the bearing with the used weight using new technologies for the production of prototypes (domestic prototypes, vacuum casting), as stated in [1,3-5].

\section{Reverse Engineering}

The essence of Reverse engineering is the transfer of a real component by means of digitization into the virtual reality environment. For the needs of Reverse engineering, it is also possible to use the computed tomography outputs, i. e. 2-dimensional (2D) sections, which are integrated into a complex 3-dimensional (3D) model of the object in the next phase of processing. The object is scanned using a measuring device, which uses software to store the coordinates of the scanned points in the modelling program and thus create a computer model of the scanned object.

There are two types of scanning procedures, contact and non-contact. The FARO Arm Platinum measuring and scanning arm enables contact and contactless digitization.

Scanning accuracy for contact measurement is $0.05 \mathrm{~mm}$; for non-contact laser measurement, the scanning accuracy is $0.03 \mathrm{~mm}[6,7]$.

\section{Rapid Prototyping}

All production methods using Rapid Prototyping (RP) are based on a 3D model, created or transferred into a Computer Aided Design (CAD) system. It is not necessary to process technical documentation for the production of a prototype and also, it is not necessary to create complex programs for the control of devices using these technologies. The processing time is an order of magnitude shorter than the time required for machines using conventional production methods. Compared to conventional production methods, prototype production takes much shorter time instead of weeks or months we can talk about days or hours.

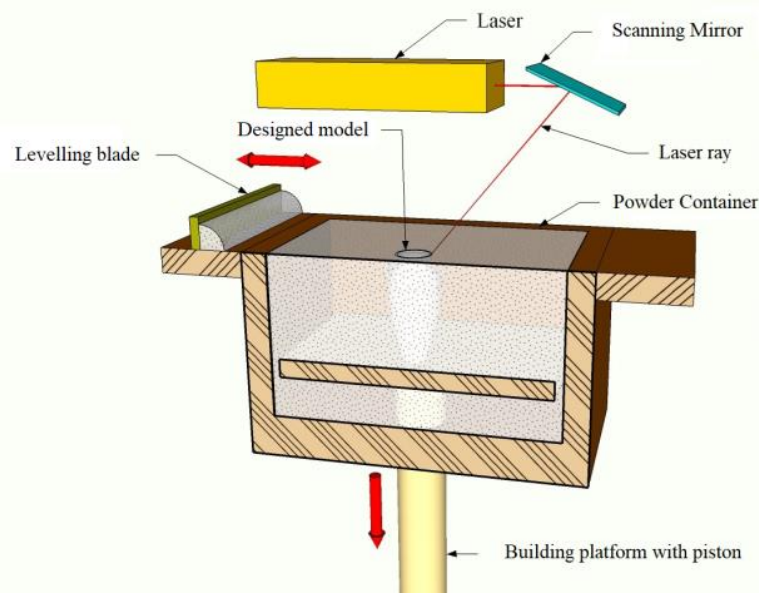

Fig. 1 The principle of a 3D printer. Source: authors 
There are currently a number of DP technologies on the market. The individual DP methods differ from each other in several aspects, such as the type of material, the method of prototyping, accuracy and, last but not least, the price. The "Formiga" 3D printer works on the principle of sintering polyamide dust using a laser. The principle of a 3D printer is shown in figure 1 [1].

\section{Vacuum Casting}

Vacuum casting a technology of casting various types of materials (plastic, rubber, wax ...) into a silicone mould. The production of the mould and consequently of the components themselves is very fast. With simple part shapes, it is possible to have the first copy after only 5-6 hours, which is incomparably faster than with conventional production methods $[1,7]$.

\section{Wheel Bearing Protection System Design}

The main idea for the development of an additional bearing protection system came due to damage to the hub of the motorcycle (Fig.2) due to the ingress of dirt into the bearing and its subsequent damage.

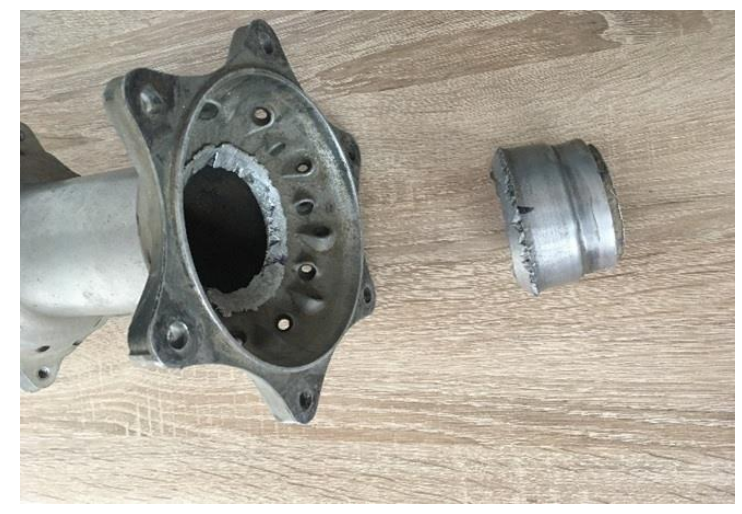

Fig. 2 Damage to the hub of the motorcycle. Source: authors

As no drawing documentation or digital form of the part was available, the part was digitialized using the Reverse engineering method. The first step was to scan the original wheel hub using a FARO Arm 3D scanner (Fig.3). The connecting surfaces and elements on the wheel hub were measured for a more accurate design of the protection system [8].

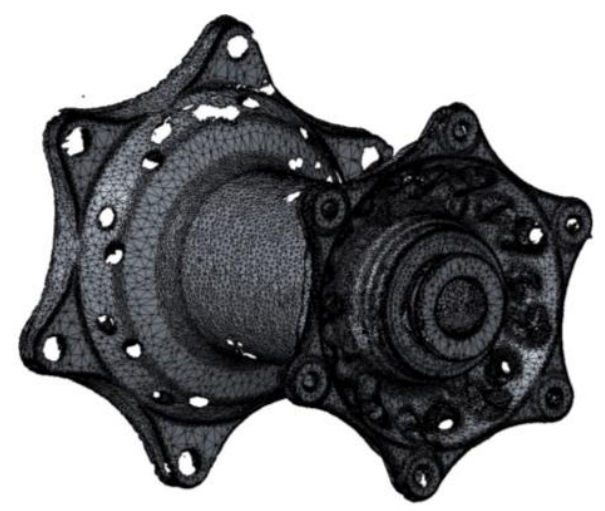

Fig. 3 Partial scan of the motorcycle hub. Source: authors 


\subsection{Protection System Design Variants}

The protection system was designed using the CAD software Catia. Three variants of the protection system were created according to the contact surfaces of the hub, the seal and the shape of the spacer. The model is designed in the way, that it fits snugly on the hub and thus protects the o-ring, bearing and wheel axle. The inner contours are designed to fit the spacer.

Figure 4 shows a 3D model of the protection system and also its half section, where the actual shape of the part can be seen.
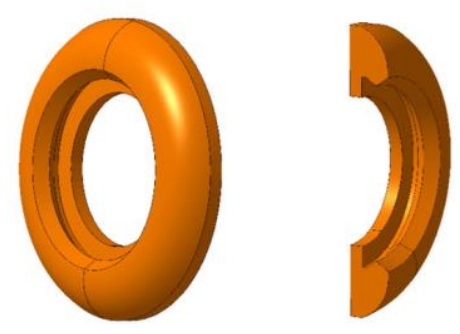

Fig. 4 Protection system design variant 1 - 3D model and its half section. Source: authors

Figure 5 shows a 3D model of the 2-nd protection system, which is structurally designed to have an arc in it towards the material to change the direction of liquid drainage during movement.
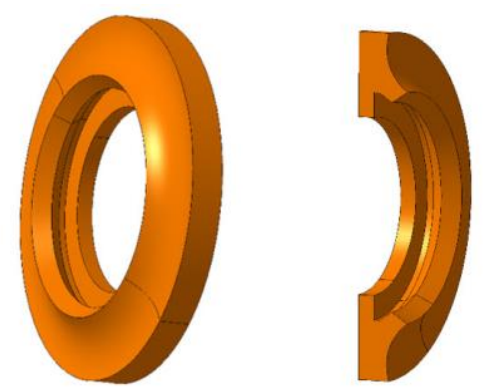

Fig. 5 Protection system design variant 2 - 3D model and its half section. Source: authors

In the figure 6, the model of the protective system is similar to that in Figure 6, it has modified inner surfaces that adhere to the spacer for tightness.
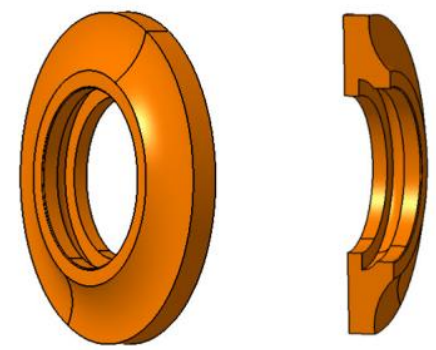

Fig. 6 Protection system design variant 3 - 3D model and its half section. Source: authors 


\subsection{Location of the Wheel Motor Bearing Protection System}

The same method of protecting the bearing against the ingress of dirt as proposed for the electric motorcycle will be used to protect the bearing of a light electric vehicle in difficult terrain. On the figure 7 , we can see the components that make up the wheel hub together with the designed bearing protection.

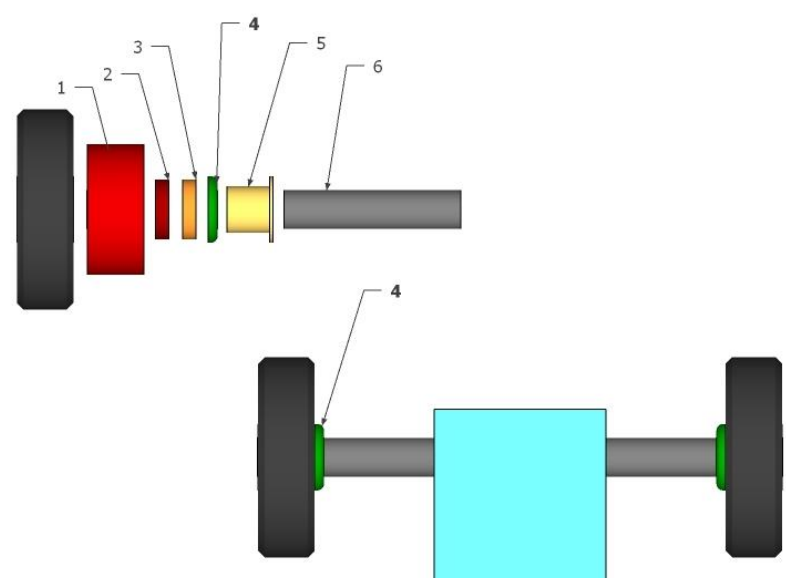

1-Wheel motor; 2-Bearing; 3-Gasket; 4-Protection system; 5-Spacer; 6-Wheel axles

Fig. 7 Location bearing protection system on the axle. Source: authors

\subsection{Protection System Material Variants}

Two types of material were selected for the production of prototypes, which would be later tested in an actual operation.

The first prototype is made on the Formiga 3D printer using the SLS method (Fig. 8). The material polyamide PA2200 is used to create the prototype. Printing with this material allows high selectivity and high resolution of details. In addition, it is characterized by good chemical resistance, low coefficient of friction and good abrasion resistance. One of the typical characteristic of sintered parts in polyamide is the perfect harmony between mechanical strength and elasticity over a wide temperature range, making this material suitable for parts with different geometries, dimensions and requirements.

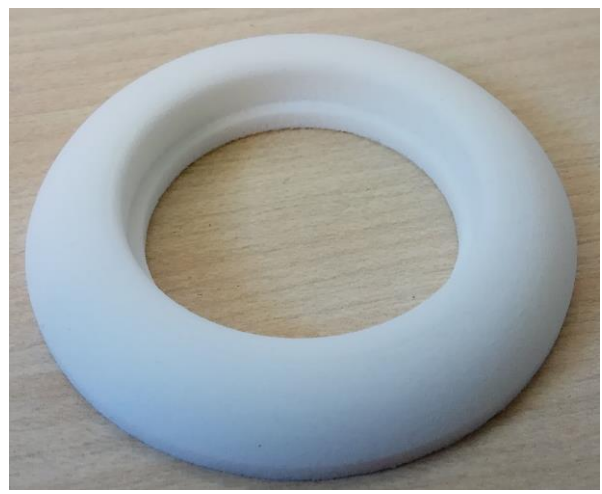

Fig. 8 Protection system design variant 1 produced by the 3D printer Formiga. Source: authors 
The second prototype is made using vacuum casting technology (Fig. 9), while the first prototype extruded from PA was used to produce the silicone mould. Subsequently, prototype number 2 was made of beta mould 60 material. It is an elastomer with a hardness of 60 Shore A, which has high expansion, high abrasion resistance and is suitable for various sealing applications.

The advantage of the vacuum casting technology is the possibility to use the already produced silicone mould for various cast material. Elastomers with a hardness of 45, 60, 70, 80, 90 Shore A are also available.

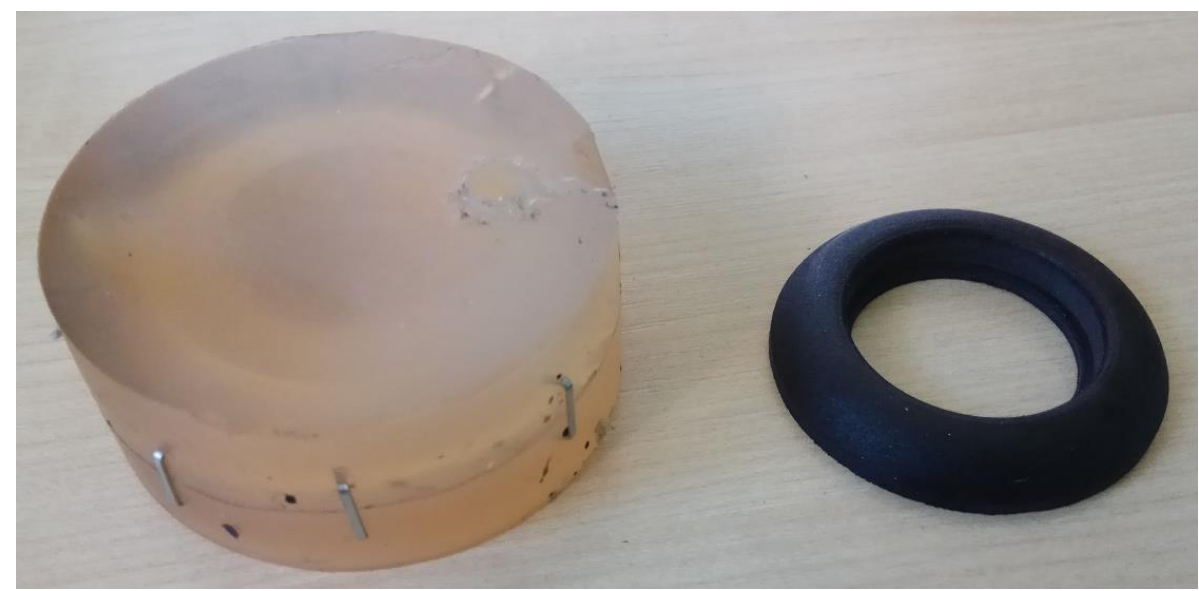

Fig. 9 Protection system design variant 1 produced by the vacuum casting technology: silicone casting mold (left); finished cast (right). Source: authors

Dimensional analysis of the prototypes was performed using the FARO Arm Platinum measuring and scanning arm. There were measured following dimensions and functional surfaces of the prototypes (Fig. 10): diameter 1, diameter 2, maximum diameter, maximum width and the flatness of the functional surface.

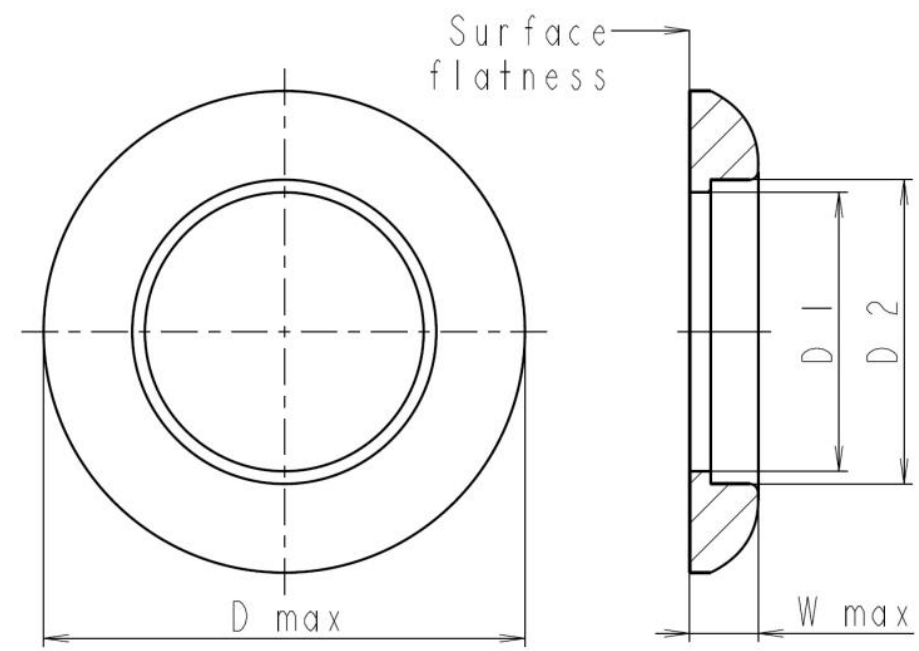

Fig. 10 Measured dimensions and surfaces of the prototype. Source: authors 
The measured dimensions of the prototype functional surfaces are listed in Table 1.

Table 1 Measured values of functional areas. Source: authors

\begin{tabular}{lccccc}
\hline $\begin{array}{l}\text { Prototype number - } \\
\text { Production method }\end{array}$ & $\begin{array}{c}\text { Diameter } \\
\text { D 1 } \\
(\mathrm{mm})\end{array}$ & $\begin{array}{c}\text { Diameter } \\
\text { D 2 } \\
(\mathrm{mm})\end{array}$ & $\begin{array}{c}\text { Diameter } \\
\text { D max } \\
(\mathrm{mm})\end{array}$ & $\begin{array}{c}\text { Width } \\
\text { W max } \\
(\mathrm{mm})\end{array}$ & $\begin{array}{c}\text { Surface } \\
\text { flatness } \\
(\mathrm{mm})\end{array}$ \\
\hline 1 - Rapid Prototyping & 32.989 & 35.998 & 56.685 & 7.988 & 0.295 \\
\hline 2 - Vacuum Casting & 33.022 & 35.009 & 56.765 & 8.049 & 0.386 \\
\hline
\end{tabular}

\section{Conclusion}

A prototype made by the rapid prototype method was produced more accurately than by the vacuum casting method. This is mainly due the mold production based on a prototype manufactured by 3D printing. Another reason is the lower accuracy of the mold and the spacing of the material. Both prototypes do not have a satisfactory flatness of the functional surface caused by the method of the prototype production. This surface has to be machined to obtain the desired flatness value [7].

The proposed wheel bearing protection system will be further tested in detail in real condition operation in a prototype vehicle with electric motors [9-11]. Subsequently, it will result to the decision, which variant and which type of material will be most suitable for fulfilling the protective function. There will also be the possibility of a structural modification or the choice of another suitable material by a proper method [12] and diagnostics [13].

\section{Acknowledgments}

„This work was supported by the Slovak Research and Development Agency under the contract No. APVV-18-0457“.

„This study was supported by Cultural and Educational Grant Agency MŠVVaŠ under the contract No. 015ŽU-4/2020“،.

\section{References}

[1] Kohar, R., Madaj, R., Sasik R. \& Gajdac I. (2018). Rapid prototyping technologies. EDIS publishing center of the University of Zilina.

[2] Sasik, R., Bastovansky R., Poljak S., Hoc. M. \& Medvecky, S. (2016). The effect of the parameters settings of a 3D printing on the mechanical properties of the manufactured prototypes. In: ICMD 2016: book of proceedings of the 57th international conference of Machine design departments, 7-9 September 2016 (115-120). Železná Ruda, Czech republic: Pilsen: University of West Bohemia. 
[3] Pastircak, R., Krivos, E. \& Lehocky, P. (2014). Using of the reverse engineering method for the production of prototype molds by patternless process technology. Archives of Foundry Engineering 2, 115-118. DOI 10.2478/afe-2014-0048.

[4] Bernat, Ł. \& Kroma, A. (2019). Application of 3D printed casting models for DisaMatch forming method. Archives of Foundry Engineering19(4), 95-98. DOI: 10.24425/afe.2019.129637.

[5] Skorulski, G. (2016). 3DP Technology for the Manufacture of Molds for Pressure Casting. Archives of Foundry Engineering 3, 99-102. DOI: 10.1515/afe-2016-0058.

[6] Poljak, S., Bastovansky, R. \& Podhora, P. (2018). Optimizing setting of open source fused deposition modeling 3D printer. In Current methods of construction design: The 59th International Conference of Machine Design Department, 11-14 September 2018 (pp. 489501). Demänovská dolina, Slovakia: Springer.

[7] Hrcek, S. \& Podhorsky J. (2004). Rapid prototyping versus CNC prototype manufacturing. Scientifics Papers of the Institute of Production Engineering and Automation of the Wrocław University of Technology. No. 85, 137-142.

[8] Caesarendra, W., Pratama, M., Kosasih, B., Tjahjowidodo, T. \& Glowacz, A. (2019) Parsimonious network based on a fuzzy inference system (PANFIS) for time series feature prediction of low speed slew bearing prognosis. Applied Sciences-Basel. 8 (12) 2656. DOI 10.3390/app8122656.

[9] Glowacz, A. (2018). Acoustic-based fault diagnosis of commutator motor. Electronics 7 (11) 299. DOI 10.3390/electronics7110299.

[10] Glowacz, A. (2018). Recognition of acoustic signals of commutator motors. Applied Sciences-Basel. 8 (12) 2630. DOI 10.3390/app8122630.

[11] Glowacz, A. (2019). Acoustic fault analysis of three commutator motors. Mechanical Systems and Signal Processing. 133 106226. DOI 10.1016/j.ymssp.2019.07.007.

[12] Chen, J.Y., Jing, L.M., Hong, T., Liu, H. \& Glowacz, A. (2020) Research on a sliding detection method for an elevator traction wheel based on machine vision. Symmetry. 12 (7) 1158. DOI 10.3390/sym12071158.

[13] Irfan, M., Alwadie, A. \& Glowacz, A. (2019) Design of a novel electric diagnostic technique for fault analysis of centrifugal pumps. Applied Sciences-Basel. 9 (23) 5093. DOI 10.3390/app9235093. 